\title{
Private health insurance plans and clinical practice
}

\author{
Serviço de Saúde Coletiva do Hospital Universitário \\ Clementino Fraga Filho, da UFRJ
}

The state, physicians, and private health care insurance plans (P-HIPs) have an obligation of offering people not only quality health care, but also care at reasonable costs. Within this framework, the Sistema Único de Saúde - SUS (Single Health System) started out to guarantee universal access to health care, a given right by the Brazilian Constitution of 1988.

Unfortunately this is far away from being the truth in Brazil. In this seminary, which is about the importation of new technologies in to health care one of the obstacles to a more efficient health system, namely the relationship between PHPs and clinical pratice will be analysed.

There are currently 35 million people covered by PHPs in Brazil. In 1994 the insurance plans disbursed about 8 billion US dollars in health care, in contrast to 6.6 billion spent by the brazilian federal government in 1992. These figures underscore trat PHPs have become one of the major, if the biggest, consumers of medical services. Therefore, their decision on forms of payment, priorities, and health care provision have a great impact in the medical labor marked and in the health system.

Gentile de Mello in 1981 labeled the INAMPS system of payment by "Unidade de Serviço", in which the higher wage to medical specialties and complementary exams, as corruptive. Nowadays, the same criticism applies to the PHIPs. This view is supported by rising demand for medical residence programs in specialties programs that use more medical procedures or not included in PHIPs programs, in an attempt to overbill patients. For instance at Hospital Universitário Clementino Fraga Filho (Rio de Janeiro) The biggest increase in candidates for medical residence in the last three years was in areas of dermatology and anesthesiology.

The requisition of complementary exams should be based on the widely known clinical epidemiology concepts of sensibility and specificity to achieve a higher diagnostic accuracy. However, in the current system complementary exams are requested to increase the number of consultations by decreasing the time spent on each consultation or by increasing the number of "fee quotients" during one consultation. On the other hand, PHIPs do not have an interest in evaluation of the impact of new technologies. New technological procedures become important because they can be presented as a major selling point in the competition for new clients. Potential banefits and increase in costs are not discussed, mainly because these costs are entirely transferred to costumers.

Fuchs, in a recent article about the american health system, estimates that in 1994 one trillion dollars were spent in health care. From this amount, 600 billion dollars were used in technologies that were unneeded or with unfavorable cost/ benefit ratio. United States of America such expenditure can be related to the practice or defencive medicine, where physicians have to defend themselves against malpractice lawsuits. There is no such a problem in Brazil and it would be unwise to start such practices. However, comercialism of medicine is already a fact and it will continue to stimulate through advertising the use of new technologies without critical though. As a consequence a new and erroneous idea of medicine is imposed to society - hystory taking and physical exam do not matter and clinical pratice has no role in disease prevention and health promotion.

To achieve better medicine medical standards and rebirth of clinical pratice in a more efficient system a new route for the brazilian health system must be discussed. This route must include a parthership and public sectors. 